\title{
Un hombre de la salud pública chilena nos ha dejado: Fernando Muñoz Porras (1948-2017)
}

$\mathrm{E}$ 1 Dr. Fernando Muñoz Porras, mi padre, fue un niño enfermizo, quizás si eso ya marcase su deriva, no lo sé. Cuando enfermaba, su madre lo llevaba a tratamientos homeopáticos, su padre, en oposición, lo llevaba a El Rápido, o a la Fuente Alemana, o simplemente a pasear. Entre esa dicotomía se crió. Era también cliente frecuente del Servicio de Urgencias del Hospital Arriarán. Su doctor, de niño, fue su tío, el gran infectólogo Mario Salcedo. Sin saberlo en ese entonces, el tío Mario, se transformó en su gran mentor.

Mi papá nació en Santiago centro. Siempre tomó micro, ¡hasta tranvía tomó! Y así lo siguió haciendo. Tomó la micro de la ciencia, luego la de la medicina, luego la de la pediatría, ahí se encontró con la infectologÍa, luego se dejó envolver por la clínica y ahí, cuando otra micro le ofrecía un trasbordo, tomó la salud pública, la epidemiología, la academia y la política.

Tras años de trabajar de manera muy consecuente con sus principios, su legado para con la salud pública de nuestro país, es amplio; en lo académico se podría decir lo mismo.

Sus pacientes, ahora adultos, lo recuerdan con mucha estima y así nos lo hicieron saber estos días. Generó grandes alianzas, amistades, hermandades, lazos diversos y frutos dulces para muchos. Lo digo, sin falsa modestia.

Mi papá llegó a la infectología porque así se comunicaba mejor con los niños, y a través de ellos, con todos.

Tuvo comunicación directa, además, con los datos, las estadísticas y la justicia. El programa "Chile Crece Contigo" fue un aporte que, junto a grandes colegas, ideó y ayudó a implementar. El actual sistema de garantías explícitas fue otro ejemplo de lo mismo. Y las paradojas del destino lo llevaron a trabajar con otra barrera contra los bichos, las vacunas, “¡Ojalá que mejor ni entren!”.

Luego vino la OPS, el cáncer y su partida. El cáncer también lo volvió a contactar con los bichos. Padeció de una leucemia muy agresiva y su inmunidad flaqueó, por la enfermedad y por el tratamiento. Seguramente un "bicharraco" lo colonizó, la ciencia no logró contenerlo y una cosa llevó a la otra y se nos fue el Doctor, el hombre público, el padre, el esposo, el abuelo.

Mi padre enfermo, siempre supo a lo que se enfrentaba, lo había estudiado, iy mi papá estudiaba harto! Y así decidió su destino. Quizás nos quiso decir, sigamos peleándole a la muerte, que la vida es lo más lindo. Así lo siento yo, mi madre me lo confirma y mi hermana me lo canta.

\section{Acá va algo de su historia:}

Salió del Instituto Nacional en 1965 y entró a Estudiar Geología (fue su segunda opción), luego de un año, dio la primera Prueba de Aptitud Académica y quedó en lista de espera en la Escuela de Medicina de la Pontificia Universidad Católica (PUC), y admitido en la Universidad Austral de Valdivia. Después subió la lista en la PUC, pero se enteró cuando ya se había matriculado en Valdivia. Nunca se arrepintió. Sus estudios lo conectaron con la ciencia médica, con la magia del sur, con grandes amigos, pero también con la pobreza y con la resiliencia de la gente.

En $4^{\circ}$ año de estudios se trasladó de vuelta a Santiago, a la Escuela de Medicina de la Universidad de Chile, Sede Norte, donde se recibió de Médico, en diciembre de 1973. Durante ese verano se trasladó a una suerte de exilio a Viña del Mar, se cortó el bigote (hecho relevante que rara vez ocurrió; "yo soy con bigote”, decía). Estando allí, ejerció como Pediatra en el Servicio de Pediatría del Hospital Gustavo Fricke y heredó temporalmente la consulta del Dr. Machiavello, y en eso estuvo hasta marzo de 1975.

Regresó a Santiago y comenzó su beca mixta de Pediatría y Salud Pública, con destino a la recién formada Escuela de Medicina de la Universidad de Chile, sede Temuco. Entonces volvió al sur, esta vez a Temuco, en el año 1978, donde ejerció como Pediatra Neonatólogo y luego en el Servicio de Infecciosos del Hospital Regional. Acá se hizo amigo del Dr. Cofré, quien gentilmente me encargó la linda labor de escribir estas líneas. Ejerció como docente de Salud Pública de la Escuela de Medicina.

En 1983 postuló a la Beca Rockefeller en la Universidad de Pensilvania de Epidemiología Clínica, y regresó a Temuco en enero de 1984. Al regreso creó la primera Unidad de Epidemiología Clínica de Chile, en la Universidad de la Frontera.

En 1990, con la llegada de la Democracia, fue nombrado Director del Servicio de Salud de la Araucanía y pronto, en el 1994 fue nombrado Subsecretario de Salud cargo al que renunció en 1998, en el Gobierno de Frei Ruiz Tagle.

Luego formó una empresa de estudios y asesorías de Salud (CLAIS), hasta que el Dr. Osvaldo Artaza, Ministro de Salud de entonces, le pidió se hiciera cargo del Departamento de Estudios del MINSAL, cargo que ocupó también en el período de Ministro de Salud Dr. Pedro García. 
Trascartón, llegó a la jefatura del Departamento de Inmunizaciones del MINSAL, compartiendo horas académicas en la Escuela de Salud Pública de la Universidad de Chile. Este año, estando hospitalizado, recibió el premio OPS 2017 por su reconocida labor en Inmunización para la región.

Mi padre era un hombre bueno, inteligente y muy culto, amante del arte y la belleza en general. Era muy amigo de sus amigos. Algo tenía el ser político que existía en él, que le permitía lograr hacer grandes cosas, sin ganarse enemigos. Tenía un profundo sentido social. También era un hombre divertido; los que lo conocieron, saben de sus chistes, anécdotas, consejos, enseñanzas y de su mirada hacia el otro, empática, cercana, cariñosa.

Mi padre vivió y murió en la suya.

No le llegaron tantos homenajes en vida, y eso no fue culpa del resto. Fue su propia responsabilidad elegir el éxito sin aspavientos.

En la foto que adjunto, mi padre en uno de sus varios viajes a Tailandia, como asistente al congreso de INCLEN (International Clinical Epidemiology Network).

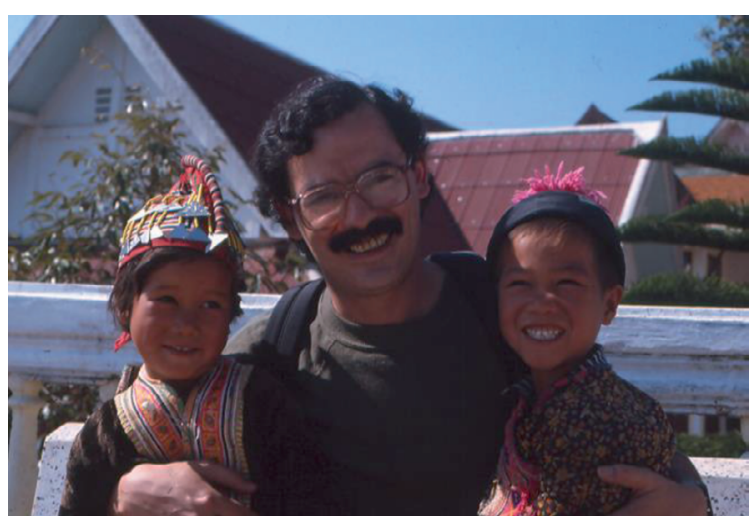

Gracias por ofrecernos la oportunidad de despedirlo así. Creo que Chile creció con él, y no sólo nosotros, los que lo conocimos y lo quisimos hasta la médula.

Dr. Emilio Muñoz Griffith

Psiquiatra, padre de familia e hijo orgulloso de mi padre 